\title{
Comprehensive Normal Phase Chromatographic Determination of Palm Vitamin E (Tocopherol, Tocotrienols and Tocomonoenol)
}

\section{$\mathrm{Ng} \mathrm{MH}^{\star}$ and Mohd Kushairi D}

Engineering and Processing Research Division, Malaysian Palm Oil Board, Selangor, Malaysia

*Corresponding author: Ng MH, Engineering and Processing Research Division, Malaysian Palm Oil Board, 6, Persiaran Institusi, Bandar Baru Bangi, 43000 Kajang, Selangor, Malaysia, Tel: 603-87694813; Fax: 603-89262971; E-mail: meihan@mpob.gov.my

Received date: June 05, 2018; Accepted date: July 13, 2018; Published date: July 23, 2018

Copyright: (C) $2018 \mathrm{Ng} \mathrm{MH}$, et al. This is an open-access article distributed under the terms of the Creative Commons Attribution License, which permits unrestricted use, distribution, and reproduction in any medium, provided the original author and source are credited.

\begin{abstract}
Palm oil has been known to be the richest source of tocotrienols, a compound belonging to the vitamin $E$ family. Besides tocotrienol, other tocols that are present in palm oil includes the tocopherol and tocomonoenol ( $\alpha-\mathrm{T}, \alpha-\mathrm{T} 1, \alpha-$ T3, $\beta-T 3, y-T 3$, and $\delta$-T3). The tocols are much sought after natural products due to their powerful antioxidative and anticancer properties. However, analysis of the tocols have always been a subject of debate due to discrepancy in techniques, instrumentations, reference materials for calibration as well as the baseline separation of all tocols components in the oil. This paper reports on a comprehensive normal phase chromatographic method using high performance liquid chromatography (HPLC) that is able to separate all the tocols in palm oil to baseline resolution with good repeatability where the presence of $\alpha-\mathrm{T} 1$ is reported and accounted for. Results from inter laboratory crosscheck proved that the method is robust, repeatable and reliable.
\end{abstract}

Keywords: HPLC; Palm; Tocomonoenol; Tocopherol; Tocotrienol; Vitamin E

\section{Introduction}

Vitamin E, also known as tocols is classified into two major homologues series, the tocopherols and tocotrienols. Each of these homologues consists of the $\alpha-, \beta-, \gamma$ - and $\delta$ - isoforms (Figure 1). While tocopherols are more commonly found in natural plants, the availability of tocotrienols is more limited. Studies have found that both tocopherols and tocotrienols are present in palm oil [1,2]. In fact, palm oil is known to contain highest amount of natural tocotrienols $[3,4]$. The amount of tocopherols and tocotrienols in crude palm oil (CPO), the oil obtained upon pressing of the palm fruits, range from 700-1000 ppm [3-5]. Earlier studies documented that palm tocols consist of $\alpha$-tocopherol $(\alpha-T), \alpha$-tocotrienol $(\alpha-T 3), \gamma$ - tocopherol $(\gamma$ $\mathrm{T}), \gamma$-tocotrienol $(\gamma$-T3) and $\delta$-tocotrienol $(\delta$-T3). Studies in later years reported the presence of $\alpha$-tocomonoenol ( $\alpha$-T1) in palm oil [5-7].

Tocopherols and tocotrienols in particular, have received vast amount of attention in recent years due to their health benefits. Studies have indicated that the tocotrienols exhibit superior antioxidative and anticancer properties [8-10]. The palm tocotrienols have also been found to provide protection against neuro degenerative diseases and cardiovascular diseases [11,12]. The palm tocotrienols have been product of interest in recent years for applications in various industries such as nutraceuticals, pharmaceuticals, cosmeceuticals, etc., The demand for tocols, especially tocotrienols has increased tremendously in recent years. As the tocotrienols is of much higher value than other tocols, accurate analysis is needed to ensure that the analytical results reflect the true concentration of the tocols in the products as well as ensuring that the analysis can be replicated at other laboratories yielding the same results.

Analysis of both tocopherols and tocotrienols using normal phase high performance liquid chromatography (HPLC) as well as supercritical fluid chromatography (SFC) have been reported in the past [13-16]. $\mathrm{Ng}$ et al. and Choo et al. reported a method for the analysis of palm tocopherols and tocotrienols using SFC [3,17]. Ong et al. on the other hand reported a comprehensive analysis of tocopherols and tocotrienols in blood serum [18].

Analysis of vitamin $\mathrm{E}$ in a wide variety of food and non-food sources using normal phase liquid chromatography coupled with UV, fluorescence and electrochromatography have also been documented in the past [19-22]. Although chromatographic analysis methods have been documented, nevertheless, the analysis result of tocopherols and tocotrienols have often raised trade disputes.

The Malaysian Palm Oil Board (MPOB), being the research agency that oversees the research activities related to palm oil and oil palm in Malaysia, has received many reports from tocols traders and producers on the discrepancy in tocols analysis. Analysis carried out using published and in-house methods adopted by these laboratories often failed to be replicated, resulting in disputes on the final volume and sales price of the tocols.

The tocols are highly potent antioxidative compounds and thus, are easily susceptible to oxidation or degradation, especially after they are dissolved in solvents for HPLC analysis. The use of individual standards for the analysis of the $\alpha-, \beta-, \gamma$ - and $\delta$-tocotrienols, as opposed to using only $\alpha-\mathrm{T}$ as reference material also left room for argument. The question on the concentration of the standards were often raised as the tocotrienols, especially $\delta$-tocotrienol is easily susceptible to oxidation. The scarcity of tocotrienols and tocomonoenol standards also contributed to the difficulty in analysis and calibrations.

While there is not much of a problem to source for individual tocotrienols reference material for research which is often a one-off affair, the need for such on a long term, day-to-day basis in trade or production laboratories incurred much cost and waiting. Official AOCS method recommended the use of $\alpha$-tocopherol as reference in 
Citation: $\mathrm{Ng} \mathrm{MH}$, Mohd Kushairi D (2018) Comprehensive Normal Phase Chromatographic Determination of Palm Vitamin E (Tocopherol, Tocotrienols and Tocomonoenol). Vitam Miner 7: 178.

Page 2 of 6

the absence of the tocotrienols standards, which is a common practice [23]. However, this also raised concern as studies in the past has reported on the discrepancy in results when only a-tocopherol is used for calibration as opposed to the use of individual tocols [5]. In addition, the concentration of a-tocomonoenol is never reported although its presence is quite significant in palm oil.<smiles>Cc1c(C)c2c(c(C)c1O)CCC(C)(CCCC(C)CCCC(C)CCCC(C)C)O2</smiles>

$\alpha$-tocopherol<smiles>CC(C)=CCC/C(C)=C/CC/C(C)=C/CCC1(C)CCc2c(C)c(O)c(C)c(C)c2O1</smiles>

$\alpha$-tocotrienol<smiles>CC(C)=CCC/C(C)=C/CC/C(C)=C/CCC1(C)CCc2cc(O)c(C)c(C)c2O1</smiles>

$\gamma$-tocotrienol<smiles>CC(C)=CCC/C(C)=C/CC/C(C)=C/CCC1(C)CCc2cc(O)cc(C)c2O1</smiles>

$\delta$-tocotrienol<smiles>CC(C)=CCC/C(C)=C/CC/C(C)=C/CCC1(C)CCc2c(C)c(O)cc(C)c2O1</smiles>

$\beta$-tocotrienol<smiles>CC(C)=CCCC(C)CCCC(C)CCCC1(C)CCc2c(C)c(O)c(C)c(C)c2O1</smiles>

$\alpha$-tocomonoenol

Figure 1: Molecular structures of tocols in palm oil.

Till date, there is no reliable official method and authentic standards for such analysis. The American Oil Chemist's Society (AOCS) has documented a normal phase chromatographic method for the analysis of tocopherols and tocotrienols, however, the method is deemed useful only when the standards for all the individual tocopherols and tocotrienols are available for calibration. In addition, there are also many complaints among tocols traders and producers that available chromatographic methods are not repeatable when crosschecked in different laboratories.

The present paper reports on a robust, repeatable and reliable normal phase chromatographic method for baseline separation of all tocopherols, tocomonoenol and tocotrienols in palm oil and / or palmbased products.

\section{Materials and Methods}

\section{Materials}

All solvents (hexane, heptane, ethyl acetate and methanol) used were of chromatographic grades purchased from Merck (Darmstadt, Germany). Tocotrienols standards ( $>97 \%$ purity) were purchased from Davos Life Sciences Pte. Ltd. (Singapore). Tocols rich fraction (TRF, CAS number 6829-55-6), which is a concentrated tocols product of palm origin, containing no less than $50 \%$ mixed tocols, was obtained from Carotino (Malaysia).

\section{Preparation of tocols standards stock solution}

$10 \mathrm{mg}$ a-tocopherol standard were weighed and transferred to a 100 $\mathrm{mL}$ volumetric flask, thereafter making up the volume to the mark with hexane. The same procedure is repeated for all other tocols standards. Another set of standards were prepared in similar manner by substituting hexane with heptane as the dissolving solvent.

\section{Determination of concentration of tocols standards}

Determination of the concentration of tocols standards were carried out by manner outlined in AOCS method (23). $10 \mathrm{~mL}$ of the $\alpha$ tocopherol standard stock solution was transferred to a $50 \mathrm{~mL}$ round bottom flask and the hexane removed by rotary evaporator at temperature less than $40^{\circ} \mathrm{C}$. The content of the flask was then transferred to a $10 \mathrm{~mL}$ volumetric flask, making up the volume with methanol.

The UV absorbance of the $\alpha$-tocopherol methanolic solution was measured at $292 \mathrm{~nm}$. The concentration of $a$-tocopherol was determined by dividing the absorbance value obtained by its $\mathrm{E}$ value $(1 \% / 1 \mathrm{~cm})$. Similar procedure is repeated for all other tocols standards. The $\mathrm{E}$ values for each corresponding tocols are as shown in Table 1. The concentration of the tocols standard determined in this manner is used for calibration of the palm TRF standards and the secondary standard.

\begin{tabular}{|c|c|c|}
\hline Tocols & $\begin{array}{l}\text { Absorbance measured at } \\
(\mathrm{nm})\end{array}$ & E Values $(1 \% / 1 \mathrm{~cm})$ \\
\hline a-tocopherol/tocotrienol & 292 & 0.0076 \\
\hline$\beta$-tocopherol/tocotrienol & 296 & 0.0089 \\
\hline Y-tocopherol/tocotrienol & 298 & 0.0091 \\
\hline$\delta$-tocopherol/tocotrienol & 298 & 0.0087 \\
\hline
\end{tabular}

Table 1: E Values of Corresponding Tocopherols and Tocotrienols. 
Citation: $\mathrm{Ng} \mathrm{MH}$, Mohd Kushairi D (2018) Comprehensive Normal Phase Chromatographic Determination of Palm Vitamin E (Tocopherol, Tocotrienols and Tocomonoenol). Vitam Miner 7: 178.

Page 3 of 6

\section{Chromatography analysis of palm tocopherols, tocomonoenol and tocotrienols}

TRF was weighed and prepared into various concentrations, ranging from $0.0006-3 \mathrm{mg} / \mathrm{mL}$ by serial dilutions using $\mathrm{n}$-heptane as the dissolving solvent. The samples prepared were then injected into a Waters e2695 Separations Module, coupled with a 2475 FLR Dectector. Column used was Phenomenex Luna II silica column, $4.6 \mathrm{~mm}$ I.D. $\times$ $250 \mathrm{~mm}$ length, $5 \mu \mathrm{m}, 100$ Á. Chromatography were carried out under condition: n-heptane: ethyl acetate $(94: 6 \mathrm{v} / \mathrm{v})$, flowrate $0.6 \mathrm{~mL} / \mathrm{min}$. The excitation and emission of fluorescence detector were set at 295 and $325 \mathrm{~nm}$ respectively.

Plot of peak area against concentration of samples (w/v) was used to determine the linear range. Limit of detection (LOD) and limit of quantitation (LOQ) were determined by the concentrations at the signal to noise $(\mathrm{S} / \mathrm{N})$ ratio of 3 and 10 respectively.

Concentrations of tocols in the samples were determined using the tocols standards prepared and calibrated earlier.

\section{Interlaboratory cross check}

A secondary standard containing the mixture $\alpha-\mathrm{T}, \alpha-\mathrm{T} 1, \alpha-\mathrm{T} 3, \gamma-\mathrm{T}$, $\gamma$-T3 and $\delta$-T3 was derived from crude palm oil using heptane. The concentration of each tocol in the mixture is calibrated using the individual tocol standards.

Interlaboratory cross check of the HPLC method was carried out by 7 independent laboratories by using the same samples, chromatographic conditions, solvent system and secondary standard, leaving the variations in the crosscheck to be the make of HPLC system and column. The results from the crosscheck were reported as Z-score or performance index of each laboratory.

The performance index represented by standard score (Z-score) of each laboratory was calculated with the formula:

$Z-$ score $=\frac{A-\text { Median }}{I Q R}$

Where,

$\mathrm{A}=$ mean of measurement results from individual laboratory.

Median=middle value of the group.

$\mathrm{IQR}=$ Interquartile range.

The Z-score magnitude (laboratory performance) is interpreted as:

$|Z|<1=$ Good

$|Z| \leq 2=$ Satisfactory.

$2<|Z|<3=$ Questionable.

$|Z| \geq 3$ = Unsatisfactory.

\section{Results}

\section{Determination of concentration of tocols standards}

The $\lambda$ max obtained in this study for each individual tocotrienols are depicted in Table 2 . The $\lambda$ max obtained are similar to those described in AOCS Method Ce 8-89. This confirms that the divisor factor, or the E values $(1 \% / 1 \mathrm{~cm})$ used for the calculation of tocols concentration as outlined by AOCS Method Ce 8-89 are accurate for both tocopherols and tocotrienols

\begin{tabular}{|l|l|l|}
\hline Tocols & $\lambda \max (\mathbf{n m}) \mathbf{1}$ & Amax $(\mathbf{n m}) \mathbf{2}$ \\
\hline$\alpha-$ Tocotrienol & 292 & 291 \\
\hline$\beta-$ Tocotrienol & 296 & 296 \\
\hline Y - Tocotrienol & 298 & 298 \\
\hline$\delta$ - Tocotrienol & 298 & 298 \\
\hline
\end{tabular}

Table 2: $\lambda \max$ of Individual Tocotrienols, 1-AOCS method; 2-This study.

\section{Normal phase chromatographic analysis of tocopherols and tocotrienols}

The chromatogram for the separation of TRF is depicted in Figure 2. The elution of the tocols in TRF of palm origin followed the order of $\alpha-$ $\mathrm{T}, \alpha-\mathrm{T} 1, \alpha-\mathrm{T} 3, \beta-\mathrm{T} 3, \gamma-\mathrm{T} 3$ and last of all, the $\delta$-T3. The whole elution took a little more than 40 minutes to be completed. Previous studies more often than not, did not report on the occurrence of the $\alpha$-T1 as it always co-elutes with $\alpha$-T. Some studies did report on the presence of $\alpha-\mathrm{T} 1$, but with poor resolution from $\alpha-\mathrm{T}$. The present method successfully separated the $\alpha-\mathrm{T}$ and $\alpha-\mathrm{T} 1$ with good resolution $(>2)$.

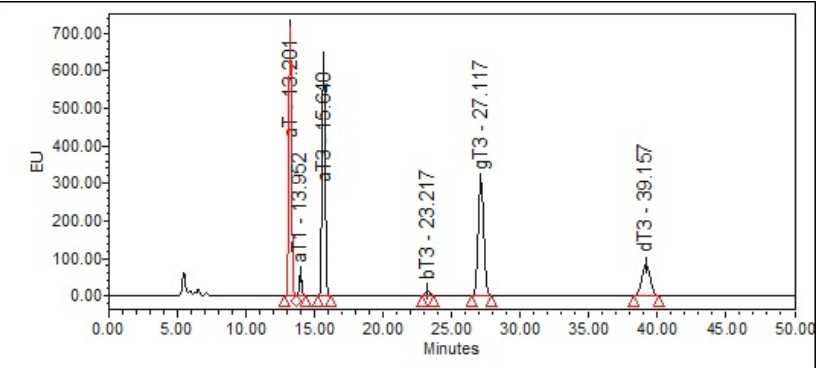

Figure 2: Chromatogram of the tocols separation in palm tocols rich fraction (TRF), Retention time: a-tocopherol (13.2), $\alpha$ tocomonoenol (13.9), $\alpha$-tocotrienol (15.6), $\beta$-tocotrienol (23.2), $\gamma$ tocotrienol (27.1), $\delta$-tocotrienol (39.1).

The linear regression coefficient for $\alpha$-T, $\alpha$-T3 and $\gamma$-T3 exceeded 0.999 while its value for $\alpha-\mathrm{T} 1, \beta-\mathrm{T} 3$ and $\delta$-T3 are $0.9918,0.9927$ and 0.9974 respectively (Table 3 ). The LOD and LOQ of $\alpha-\mathrm{T}$ of this study (2.96 and $9.86 \mathrm{mg} / \mathrm{mL}$ respectively) are significantly lower than previous studies $(14,24)$.

\begin{tabular}{|l|l|l|l|l|}
\hline & $\begin{array}{l}\text { Signal to } \\
\text { Noise }\end{array}$ & $\begin{array}{l}\text { Correlation } \\
\text { Coefficient }\end{array}$ & $\begin{array}{l}\text { Limit of } \\
\text { Detection }\end{array}$ & $\begin{array}{l}\text { Limit } \\
\text { Quantitation }\end{array}$ \\
\hline a-T & 3.6365 & 0.9992 & 2.96 & 9.86 \\
\hline a-T1 & 2.8485 & 0.9918 & 0.48 & 10.58 \\
\hline a-T3 & 3.0842 & 0.999 & 3.18 & 42.35 \\
\hline b-T3 & 3.969 & 0.9927 & 0.13 & 1.73 \\
\hline g-T3 & 3.5927 & 0.999 & 2.4 & 32.03 \\
\hline d-T3 & 4.9505 & 0.9974 & 1.03 & 13.8 \\
\hline
\end{tabular}

Table 3: Signal to Noise, LOD \& LOQ of Individual Tocols. 
Citation: $\mathrm{Ng} \mathrm{MH}$, Mohd Kushairi D (2018) Comprehensive Normal Phase Chromatographic Determination of Palm Vitamin E (Tocopherol, Tocotrienols and Tocomonoenol). Vitam Miner 7: 178.

Page 4 of 6

The peak area versus concentration of the tocols are depicted in Figure 3. Linear range of individual tocols for the said method are depicted in Figures 4-9.

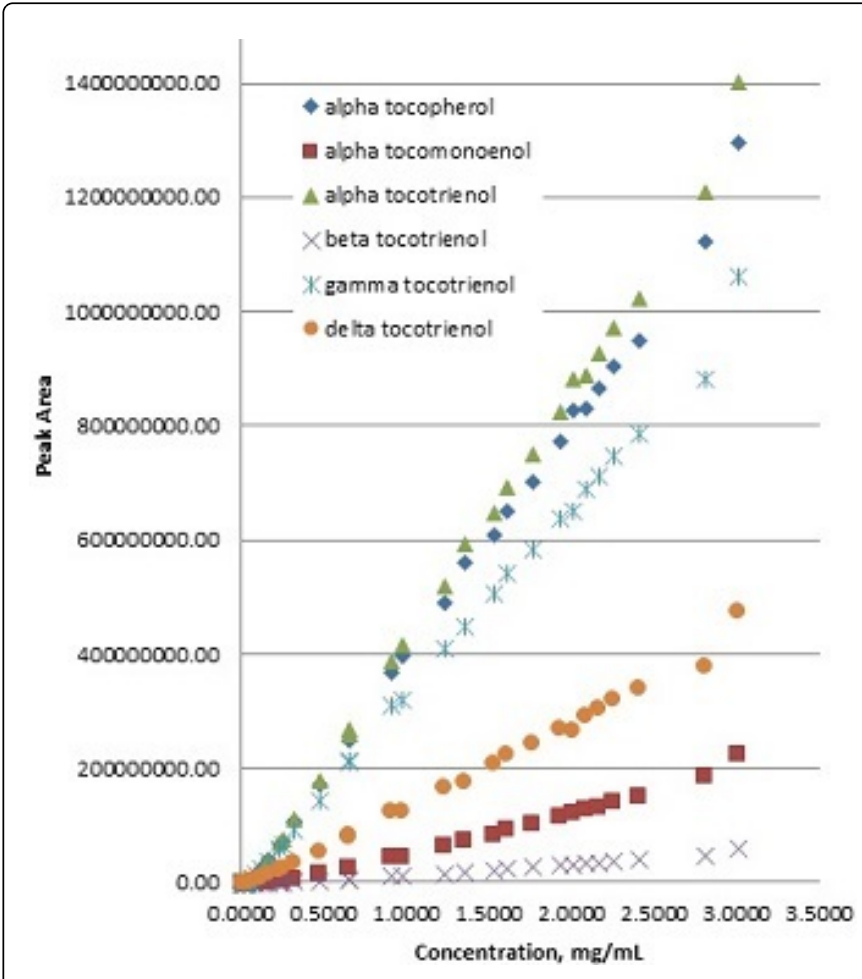

Figure 3: Peak Area vs sample concentrations of palm tocols.

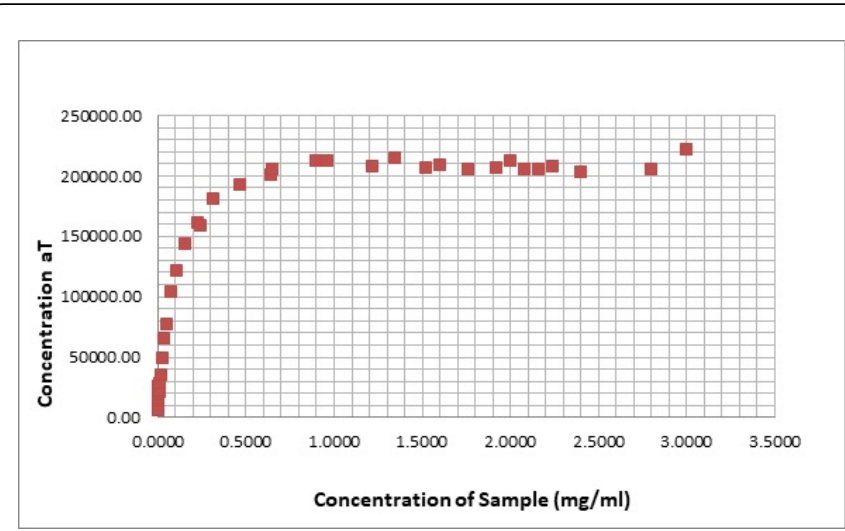

Figure 4: Concentration of individual vs concentration of sample for $\alpha-T$ in which its linear range can be deduced.

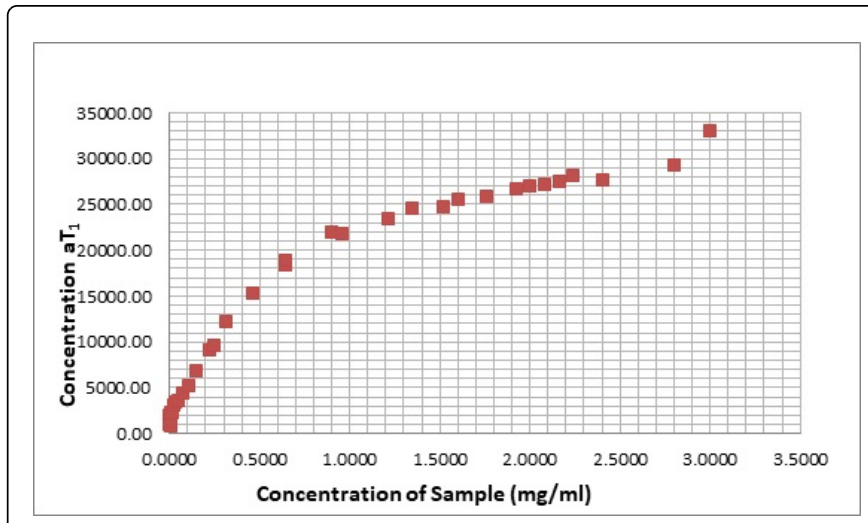

Figure 5: Concentration of individual vs concentration of sample for $\alpha-\mathrm{T} 1$ in which its linear range can be deduced.

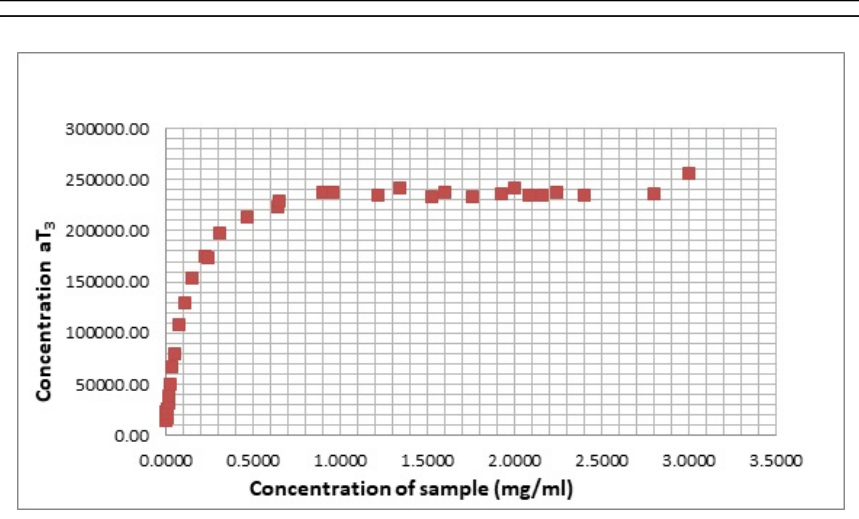

Figure 6: Concentration of individual vs concentration of sample for $\alpha-\mathrm{T} 3$ in which its linear range can be deduced.

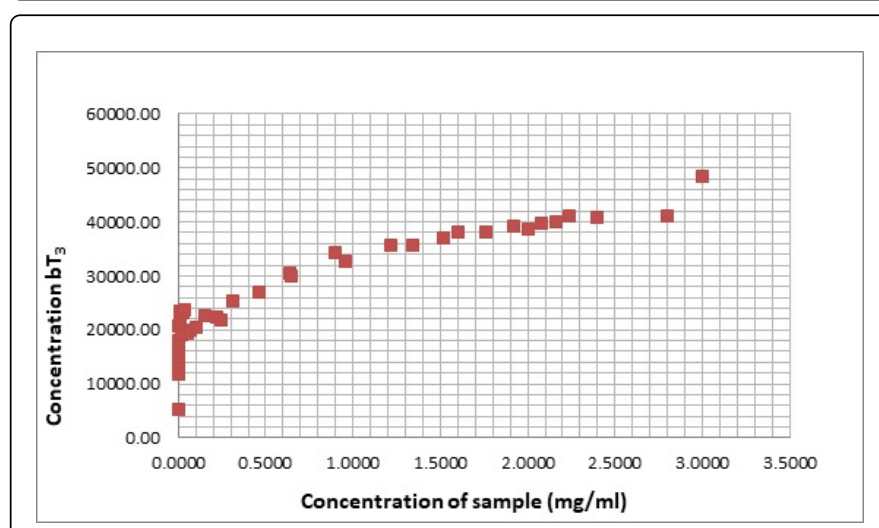

Figure 7: Concentration of individual vs concentration of sample for $\beta$-T3 in which its linear range can be deduced. 


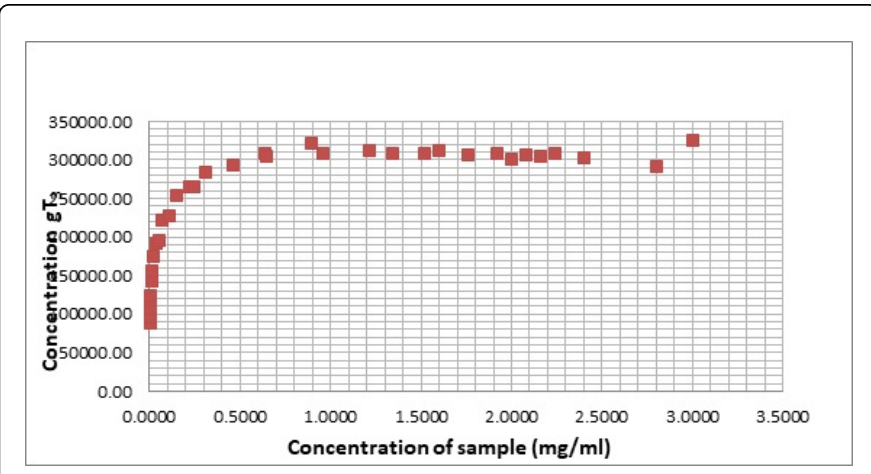

Figure 8: Concentration of individual vs concentration of sample for $\gamma$-T3 in which its linear range can be deduced.

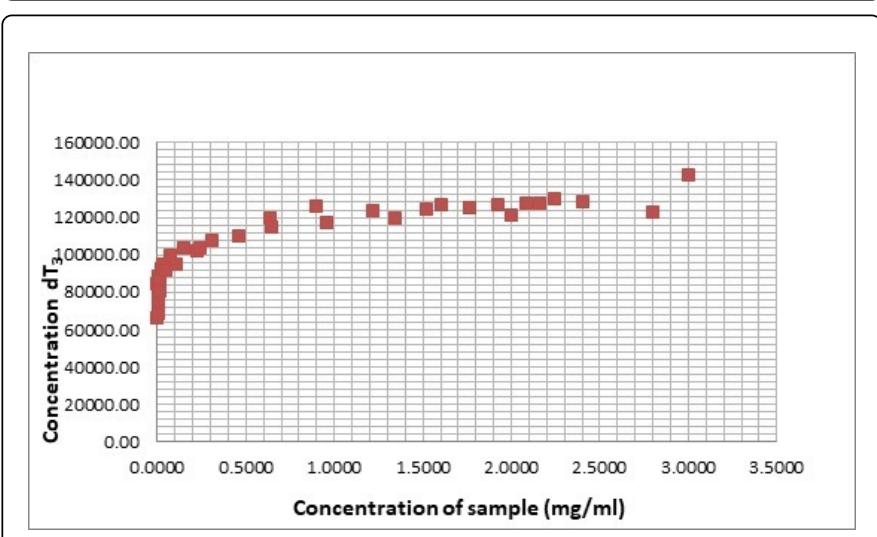

Figure 9: Concentration of individual vs concentration of sample for $\delta$-T3 in which its linear range can be deduced.

\section{Interlaboratory cross check}

Interlaboratory crosscheck offers insight into the robustness and adaptability of the chromatographic method across various brands of HPLC systems as well as column. Table 4 depicts the $\mathrm{z}$ score of the analytical results on the same sample obtained from seven laboratories.

\begin{tabular}{|l|l|}
\hline Lab Code & SampleA \\
\hline P1 & 1.59 \\
\hline P2 & 0.74 \\
\hline P3 & 0.08 \\
\hline P4 & 0 \\
\hline P5 & 0.06 \\
\hline P6 & 1.13 \\
\hline P7 & 0.15 \\
\hline
\end{tabular}

Table 4: Z Score of Interlaboratory Cross Check, Indication of Z-score, $|Z|<1=$ Good; $|Z| \leq 2$ =Satisfactory; $2<|Z|<3=$ Questionable; $|Z| \geq$ $3=$ Unsatisfactory.
The performance of five laboratories is 'good', while performance from the remaining two laboratories are 'satisfactory'. Overall, the crosscheck proved that the normal phase chromatography method in the present study can be replicated.

\section{Discussion}

\section{Determination of concentration of tocols standards}

AOCS method Ce 8-89 outlined that the wavelengths where maximum UV is absorbed $(\lambda \max )$ for tocopherol can be used for their respective tocotrienol, despite the difference in their molecular formula and structure. However, there was still concern that the tocotrienols may not absorb maximum UV at the same wavelengths as the tocopherols due to the difference in their response in UV. As the divisor factor used for the determination of tocols concentration is derived from $\mathrm{E}$ values $(1 \% / 1 \mathrm{~cm})$ of the respective tocols, which in turn, is different at different wavelengths, it is thus important to ascertain that the correct $\lambda \max$ and $\mathrm{E}$ values are observed and used. For example, the E values $(1 \% / 1 \mathrm{~cm})$ of $\alpha-\mathrm{T}$ in methanolic solution is 76 at $292 \mathrm{~nm}$. Thus, a $1 \mathrm{mg} / \mathrm{mL}$ a-T solution will have an absorbance of 0.0076 at $292 \mathrm{~nm}$. Using the correct $\mathrm{E}$ values is important for accurate calculation of the tocols' concentrations.

As depicted in Table 2, there is only a slight deviation $( \pm 1 \mathrm{~nm})$ for the $\lambda$ max of $\alpha-\mathrm{T} 3$ as opposed to the literature. As such, the $\lambda \max$ and $\mathrm{E}$ values of individual tocopherols can be used for individual tocotrienols as well. UV spectroscopy was used to only determine the maximum absorption value of the tocols for calculation of standards concentrations and not as the detection of tocols from the HPLC as fluorescence detection in HPLC is a better detector choice for the tocols. Fluorescence detector offers higher sensitivity where tocols is concern.

\section{Chromatography analysis of tocopherols and tocotrienols}

The similarity in the core chromanol ring structure of the vitamin $\mathrm{E}$ (tocopherols, tocomonoenol and tocotrienols) rendered these compounds to have very similar chromatographic characteristic. It was a challenge to separate these compounds into baseline resolution. This was the reason the presence of $\alpha-\mathrm{T} 1$ in palm oil was not reported as it co-eluted with other tocols. The amount of $\alpha-\mathrm{T} 1$ has been reported to be ca. $2 \%$ of total tocols present in palm oil. The amount seemed insignificant in the crude palm oil (CPO) itself where the total tocols concentration is only about 700-1000 ppm. However, its concentration is greatly enhanced and concentrated in other palm based downstream products. A $50 \%$ mixed TRF for example, contains as much as 18,000 ppm of $\alpha-T 1$ and thus the financial implication is large. As such, it is important for the $\alpha-\mathrm{T} 1$ to be analyzed and reported. Presence of $\alpha-\mathrm{T} 1$ in palm oil was reported in recent studies by other means of analysis such as countercurrent and reversed phase chromatography [6,7]. In terms of normal phase chromatography, where the official test methods for vitamin $\mathrm{E}$ analysis (AOCS Ce 8-89, ISO 9936 and IUPAC2.432) failed to resolve the $\alpha-\mathrm{T}, \alpha-\mathrm{T} 1$ and $\alpha-\mathrm{T} 3$ peaks, the present method can achieve that.

Statistical analysis revealed that the correlation coefficient is lowest for $\alpha-\mathrm{T} 1$ (0.9918) and highest for $\alpha-\mathrm{T}$ (0.9992). $\beta$-T3 has the lowest LOD and LOQ at $0.13 \mathrm{mg} / \mathrm{mL}$ and $1.73 \mathrm{mg} / \mathrm{mL}$ respectively while the LOD and LOQ for a-T3 were highest at $3.18 \mathrm{mg} / \mathrm{mL}$ and $42.35 \mathrm{mg} / \mathrm{mL}$ respectively. These values are significantly lower than previous reports 
$(14,24)$. This shows that the present method can analyse the tocols more accurately.

The linear range for the individual tocols can be deduced from Figure 4-9.

The amount of palm tocols varies from as little as $700 \mathrm{ppm}$ to $900,000 \mathrm{ppm}$, depending on the sources. The crude palm oil (CPO) contains $700-1,000$ ppm tocols, while its amount is much higher in the TRF. As such, there is no one universal linear range for all sources that is suited for the analysis of tocols by HPLC. The linear range reported in this study $(0.52-2.10 \mathrm{mg} / \mathrm{mL})$, is only applicable to sources containing more than $500,000 \mathrm{ppm}$ tocols. As such, as a rule of thumb, a generally accepted analysis of the palm tocols must fulfill the following 1) resolution of more than 2 for all compounds, (2) presence of $\alpha-\mathrm{T} 1$ is reported and 3) the LOD and LOQ is fulfilled.

\section{Interlaboratory cross check}

Results from the interlaboratory crosscheck revealed that the Zscore for each tocol to be $<1$. Amount of individual tocols and total tocols as calibrated using the secondary standard was in good agreement between the laboratories. Presence of $\alpha-T 1$ was reported by all laboratories and the resolution of all the peaks are $>2$. This shows that the method is repeatable, and the secondary standard is sufficient for the determination of the tocols in palm without the need for the individual standards in every analysis. However, the content of the secondary standard should be calibrated against the individual standards from time to time to ensure its quality.

\section{Acknowledgements}

The authors wish to thank the Supporting Staff of the Clean and Emerging Technologies Group of the Engineering and Processing Research Division for their technical support.

\section{References}

1. Chandrasekaram K, Ng MH, Choo YM, Chuah $\mathrm{CH}$ (2009) Individual Vitamin E Components in Palm Phytonutrients Concentrate using high Performance Liquid Chromatography with Fluorescence Detection. Journal of Oil Palm Research 21: 621-626.

2. Ng MH, Choo YM (2012) Chromatographic Analysis of Tocopherols and Tocotrienols in Palm Oil. Journal of Chromatographic Science 50: 283286.

3. Ng MH, Choo YM, Ma AN, Chuah $\mathrm{CH}$, Mohd $\mathrm{AH}$ (2004) Isolation of Palm Tocols using Supercritical Fluid Chromatography. Journal of Chromatographic Science 42: 536-539.

4. Ng MH, Choo YM, Ma AN, Chuah CH, Hashim MA (2004) Separation of Vitamin E (Tocopherol, Tocotrienol and Tocomonoenol) in Palm Oil Lipids 39: 1031-1035.

5. Goh SH, Choo YM, Ong ASH (1985) Minor Constituents of Palm Oil. Journal of American Oil Chemists Society 62: 237-240.

6. Irías-Mata A, Stuetz W, Sus N, Hammann S, Gralla K, et al. (2017) Tocopherols, Tocomonoenols, and Tocotrienols in Oils of Costa Rican Palm Fruits: A Comparison between Six Varieties and Chemical versus Mechanical Extraction. Journal of Agricultural and Food Chemistry 65: 7476-7482.

7. Müller M, Hammann S, Vetter W (2018) Countercurrent chromatographic isolation and purification of $11^{\prime}$ - $\alpha$-tocomonoenol from the vitamin E extract of palm oil. Food Chemistry 256: 327-332.
8. Nesaretnam K, Wong WY, Mohd Basri W (2007) Tocotrienols and cancer: Beyond antioxidant activity. European Journal of Lipid Science and Technology 109: 445-452.

9. Nesaretnam K, Teoh HK, Sevaduray KR, Brono RS, Emily H (2008) Modulation of the cell growth and apoptosis response in human prostate cancer cells supplemented with tocotrienols. European Journal of Lipid Science and Technology 111: 23 -31.

10. Nesaretnam K, Guthrie N, Chambers AF, Caroll KK (1995) Effect of Tocotrienols on the Growth of Human Breast Cancer Cell Line in Culture. Lipids 30: 1139-1143.

11. Miyazagawa T, Inokuchi $H$, Hirokane $H$, Tsuzuki T, Nakagawa $K$, et al. (2004) Anti-angiogenic Potential of Tocotrienol in vitro. Biochemistry 69: 67-69.

12. Chandan KS, Cameron R, Savita K (2010) Palm Oil-Derived Natural Vitamin E $\alpha$-Tocotrienol in Brain Health and Disease. Journal of American College Nutrition 29: 314S-323S.

13. Zheng YB, Huang BF, Ren YP (2016) Simultaneous determination of eight vitamin $\mathrm{E}$ isomers and vitamin $\mathrm{A}$ in foods by normal-phase high performance liquid chromatography. Chinese Journal of Chromatography 34: 692-696.

14. Gee PT, Liew CY, Thing MC, Gay MC (2016) Vitamin E analysis by ultraperformance convergence chromatography and structural elucidation of novel a-tocodienol by high-resolution mass spectrometry. Food Chemistry 196: 367-373.

15. Kornél N, Courtet-Compondu MC, Holst B, Kussmann M (2007) Comprehensive Analysis of Vitamin E Constituents in Human Plasma by Liquid Chromatography-Mass Spectrometry. Analytical Chemistry 79: 7087-7096.

16. Neagu M, Soceanu G, Bucur AC (2015) Validation of a HighPerformance Liquid Chromatography method for the determination of vitamin $\mathrm{A}$, vitamin $\mathrm{D} 3$, vitamin $\mathrm{E}$ and benzyl alcohol in a veterinary oily injectable solution. Medicamentul Veterinar / Veterinary Drug 9: 84-88.

17. Choo YM, Ng MH, Ma AN, Chuah CH, Mohd AH (2005) Application of Supercritical Fluid Chromatography in the Determination of Palm Squalene, Carotenes, Vitamin E and Sterols in Palm Oil. Lipids 40: 429432 .

18. Ong S, Xu CH, Teo VH, Yap WN, Zaiden N, et al. (2010) Comprehensive Quantification of Palm Vitamin E by Normal Phase High Performance Liquid Chromatography. Palm Oil Developments 52: 11-17.

19. Dauqan E, Sani HA, Abdullah A, Muhamad H, Top AG (2011) Vitamin E and Beta Carotene Composition in Four Different Vegetable Oils. American Journal of Applied Sciences 8: 407-412.

20. Henry CW, Fortier CA, Warner IM (2001) Separation of Tocopherol Isomers Using Capillary Electrochromatography: Comparison of Monomeric and Polymeric C30 Stationary Phase. Analytical Chemistry 73: 6077-6082.

21. Dunphy PJ, Whittle KJ, Pennock JF, Morton RA (1965) Identification and Estimation of Tocotrienols in Hevea latex. Nature 207: 501.

22. Yap SP, Julianto T, Wong JW, Yuen KH (1999) Simple High Performance Liquid Chromatographic Method for the Determination of Tocotrienols in Human Plasma. Journal of Chromatography B: Biomedical Sciences and Applications 735: 279.

23. AOCS Official Method (2017) Tocopherols and Tocotrienols in Vegetable Oils and Fats by HPLC Ce 8-89.

24. Gong X, Qi N, Wang X, Li J, Lin L (2014) A New Method for the Determination of $\alpha$-tocopherol in tropical fruits by Ultra Performance Convergence Chromatography with Diode Array Detector. Food Analytical Methods 7: 1572-1576. 